\title{
Differential Expression Pattern of $S$-Adenosylmethionine Synthetase Isoenzymes During Rat Liver Development
}

\author{
Beatriz Gil, ${ }^{1}$ Marta Casado, ${ }^{2}$ María A. Pajares, ${ }^{1}$ Lisardo Boscá,${ }^{2}$ José M. Mato, ${ }^{1}$ Paloma Martín-Sanz, ${ }^{2}$ \\ AND Luis Alvarez ${ }^{1}$
}

The pattern of expression of liver-specific and extrahepatic $S$-adenosylmethionine (SAM) synthetase in developing rat liver was established by determining steadystate levels of the respective messenger RNAs (mRNAs) and protein content. Levels of liver-specific SAM synthetase mRNA increased progressively from day 20 of gestation, increased 10-fold immediately after birth, and reached a peak at 10 days of age, decreasing slightly by adulthood. Conversely, mRNA levels of extrahepatic isoenzyme decreased toward birth, increased threefold in the newborn, and decreased further in the postnatal life, reaching a minimum in the adult. Similar expression profiles were observed in isolated hepatocytes, indicating that both mRNAs are differentially regulated in the same cell type. Western blot analysis showed that levels of immunoreactive liver-specific isoenzyme followed a trend similar to the mRNA, indicating that developmental regulation of this enzyme is mediated at the mRNA level. Developmental patterns of expression of albumin and $\alpha$-fetoprotein (AFP) mRNAs were closely related to those for liver-specific and extrahepatic isoenzymes, respectively. Therefore, it is suggested that liverspecific SAM synthetase may be a marker for hepatocyte differentiation. Incubation of primary cultures of hepatocytes from 21-day-old fetuses with permeant cyclic adenosine monophosphate (cAMP) analogues elicited an up-regulation of the mRNA for the liver-specific isoenzyme with a concomitant down-regulation of the extrahepatic message, suggesting a physiological role for the increased postnatal glucagonemia in the control of this isoenzyme switching. In contrast with the isoenzyme expression profiles, the levels of SAM, the product of SAM synthetase reaction, were determined to be greater during gestation than in immediate postnatal periods. These results indicate that synthesis and utilization of SAM may be regulated differentially in fetal and adult hepatocytes. (HEPATOLOGY 1996;24:876-881.)

Growth and development of mammalian liver proceed with characteristic alterations of the enzyme pool through which it acquires the capability of coping with the demands of altered environmental conditions imposed by birth and postnatal life.

Abbreviations: SAM, $S$-adenosylmethionine; cDNA, complementary DNA; mRNA, messenger RNA; cAMP, cyclic adenosine monophosphate; AFP, $\alpha$-fetoprotein.

From the ${ }^{1}$ Instituto de Investigaciones Biomédicas, Consejo Superior de Investigaciones Cientificas, Madrid, Spain; and the ${ }^{2}$ Instituto de Bioquímica, Facultad de Farmacia (CSICUCM), Madrid, Spain.

Received January 10, 1996; accepted May 21, 1996.

Supported by grants $94 / 0231$ and $95 / 0966$ from the Fondo de Investigaciones Sanitarias, grant PB 94/0087 from the Dirección General de Investigaciones Científicas, and grant SCI*-CT92-0780 from the Science program of the European Community and by Europharma. Drs. Casado and Gil are fellows of the Ministerio de Educación y Ciencia.

Drs. Gil and Casado contributed equally to this article.

Address reprint requests to: Luis Alvarez, Ph.D., Instituto de Investigaciones Biomédicas, Consejo Superior de Investigaciones Cientificas, Arturo Duperier, 4, 28029 Madrid, Spain.

Copyright (C) 1996 by the American Association for the Study of Liver Diseases. 0270-9139/96/2404-0020\$3.00/0
This process, which involves the expression of new enzymes and changes in the concentration of those already present, is known as enzymic differentiation ${ }^{1}$ and concerns a number of enzymes accounting for main liver functions, ${ }^{1,2}$ among them, $S$-adenosylmethionine (SAM) synthetase.

SAM synthetase (EC 2.5.1.6) catalyzes the only known biosynthetic route to SAM, the major donor of methyl groups, from adenosine triphosphate and methionine. ${ }^{3}$ This reaction is especially important in the liver, where as much as $48 \%$ of the methionine taken by the diet is metabolized and up to $85 \%$ of all transmethylation reactions occur. ${ }^{4,5}$ According to its crucial role in this organ, mammals express a liver-specific SAM synthetase isoenzyme, whereas in other tissues, the socalled extrahepatic or kidney-type SAM synthetase is present (reviewed by Kotb and Geller ${ }^{6}$ and Mato et al. ${ }^{7}$ ). The functional relevance of this pattern of expression of SAM synthetase remains unclear, although some suggestions have been addressed. ${ }^{6}$ These isoenzymes seem to be encoded by different genes, as judged by sequence comparison of the corresponding complementary DNAs (cDNAs). ${ }^{8-14}$

Earlier studies showed that marked changes in SAM synthetase activity occur during liver development. Thus, in mouse liver, Hancock ${ }^{15}$ reported a rapid increase in SAM synthetase activity after birth from trace activities in the near-term fetus to a peak value at the age of 21 days. Finkelstein ${ }^{16}$ also reported a significantly greater SAM synthetase activity in the suckling and weaning rat than in the adult. In a comprehensive study, Chase et al. ${ }^{17}$ found that specific activity began to increase in late fetal life, reaching a maximum 2 days after birth and decreasing slightly by adulthood. Changes in SAM synthetase isoenzymes during development have also been reported. Based on their respective kinetic properties and on immunohistochemical analysis, it has been shown that rat liver-specific SAM synthetase is expressed only in adult liver, whereas the extrahepatic isoenzyme is predominantly expressed in fetal liver and faintly detected in the adult organ. ${ }^{18,19}$ In humans, it has also been reported that the extrahepatic form is weakly expressed in adult liver, and in contrast to the rat, the liver-specific form is present at very low levels in fetal liver. ${ }^{13,14,20}$

Altogether, the data available suggest that a SAM synthetase isoenzyme switching occurs during liver development. To date, however, a comprehensive survey of developmental profile of these isoenzymes has not been performed. In the present study, we have delineated the developmental pattern of messenger RNA (mRNA) expression of both SAM synthetases in rat liver. Special attention has been paid to the mechanism that controls this switch of isoenzymes and to the levels of SAM at different stages of liver development.

\section{MATERIALS AND METHODS}

Animals. Pregnant, 3-month-old, albino Wistar rats (weight range, 300-350 g) were fed a standard laboratory diet and were killed for the experiment between 9 and 10 AM. Gestation age was assessed following standard criteria. ${ }^{21}$ Fetuses of the indicated age were delivered by cesarean section after the mother was anesthestized with 
Nembutal (Abbott Labs, North Chicago, IL). Animals were treated following the institution's criteria for the care and use of laboratory animals.

Isolation of Fetal, Neonatal, and Adult Hepatocytes. Fetal and neonatal liver hepatocytes were prepared by a nonperfusion collagenase dispersion method. ${ }^{22}$ Briefly, the tissue was chopped with scissors and incubated for 30 minutes at $37^{\circ} \mathrm{C}$ with $\mathrm{Ca}^{2+}$-free Krebs'-bicarbonate buffer containing $0.5 \mathrm{mmol} / \mathrm{L}$ ethylene glycol-bis ( $\beta$-aminoethyl ether)- $N, N, N^{\prime}, N^{\prime}$-tetraacetic acid under continuous gassing with carbogen $\left(\mathrm{O}_{2} / \mathrm{CO}_{2} ; 19: 1\right)$. The cell suspension was centrifuged (50g for 2 minutes), and the cell pellet was resuspended and incubated for 60 minutes in the presence of $2.5 \mathrm{mmol} / \mathrm{L}$ of $\mathrm{Ca}^{2+}$ and $0.5 \mathrm{mg} / \mathrm{mL}$ of collagenase. At the end of the incubation period, the cells were centrifuged and filtered through nylon membranes of 500-, 100-, and $50-\mu \mathrm{m}$ mesh. The contamination of hematopoietic cells of the preparation was determined by microscopic observation and was $<5 \%$. Cell viability was always $>90 \%$. Adult hepatocytes were prepared following the classical collagenase perfusion method. ${ }^{23}$

When hepatocytes were used in culture, the cell suspension was washed twice with sterile Dulbecco's modified Eagle medium and then resuspended in the same medium supplemented with $50 \mu \mathrm{g} /$ $\mathrm{mL}$ of penicillin $\mathrm{G}$ and $50 \mu \mathrm{g} / \mathrm{mL}$ of streptomycin. Fetal hepatocytes $\left(3-4 \times 10^{6}\right)$ were plated in 6 -cm tissue-culture dishes in $2.5 \mathrm{~mL}$ of Dulbecco's modified Eagle medium supplemented with $10 \%$ fetal calf serum. After 4 hours of incubation to facilitate cell attachment to the plate, the medium was aspirated, the plates were washed twice with phosphate-buffered saline to remove the nonadherent cells and filled with $2 \mathrm{~mL}$ of Dulbecco's modified Eagle medium, containing 10 $\mathrm{mg} / \mathrm{mL}$ of fatty acid-free bovine serum albumin. Hormone additions were made so that the changes in the total incubation volume were $<2 \%$. Dexamethasone and insulin were added to a final concentration of $1 \mu \mathrm{mol} / \mathrm{L}$; prolactin was added at $100 \mathrm{nmol} / \mathrm{L}$, and $\mathrm{ph}$-cyclic adenosine monophosphate (cAMP) plus theophylline were added at $100 \mu \mathrm{mol} / \mathrm{L}$. Hormones and other agents were obtained from Novo Industri A/S (Copenhagen, Denmark), Sigma Chemical Co. (St. Louis, MO), and Merk AG (Darmstadt, Germany).

cDNA Probes. A cDNA comprising 1,147 base pairs of the rat extrahepatic SAM synthetase was obtained by reverse-transcription coupled to polymerase chain reaction. Primers were designed according to the published cDNA sequence. ${ }^{10}$ The first cDNA strand was synthesized from $3 \mu \mathrm{g}$ of rat kidney Poly (A) ${ }^{+}$(Clontech, Palo Alto, CA) RNA using $200 \mathrm{U}$ of Moloney murine leukemia virus reverse-transcriptase (Superscript II; GIBCO BRL, Paisley, Scotland) and the downstream primer (5'-AGCTGTCCCTACCAAAGTGGC- 3 '), complementary to nucleotide residues 1133-1153 of the extrahepatic SAM synthetase sequence. The cDNA was then subjected to polymerase chain reaction amplification with the above primer and the upstream primer (5'-CGGGCAGCTCAACGGCTTCCA-3'), corresponding to nucleotides 6-26. Amplification was performed as described previously ${ }^{24}$ but using the thermostable DNA polymerase Dynazyme (Finnzymes, Oy, Finland). The resulting fragment was purified, inserted into the SmaI site of pUC18 plasmid, and sequenced by the dideoxy chain termination method ${ }^{25}$ to confirm its authenticity. Other cDNA fragments used as probes were as follows: a 2.2-kilobase EcoRI fragment of the rat liver-specific SAM synthetase cDNA $\mathrm{SSRL}^{9}$; a fragment comprising 1.1 kilobases of rat albumin cDNA clone pRSA13 ${ }^{26}$; a 0.6 -kilobase fragment of the cDNA for rat $\alpha$-fetoprotein (AFP) ${ }^{27}$; and a cDNA for the 18S ribosomal RNA inserted into plasmid pBR322 was used for normalization.

Northern Blot Analysis. Total RNA was isolated by the guanidinium isothiocyanate method. ${ }^{28}$ Aliquots of RNA $(30 \mu \mathrm{g})$ were size fractionated on a $0.9 \%$ agarose denaturing gel and transferred to Nytran membranes (Schleicher and Schuell, Keene, NH). Prehybridization and hybridization were performed as described previously. ${ }^{29}$ The probes were random primed labeled with $\left[\alpha-{ }^{32} \mathrm{P}\right]$ deoxycytidine triphosphate using the Readyprime labeling kit (Amersham Ltd., Little Chalfont, England). The filters were scanned on a Molecular Imager GS-250 (Bio-Rad Laboratories, Richmond, CA), and quantitative analysis was performed running the Phosphor analyst software (Bio-Rad Laboratories).

Western Blot Analysis. Samples from rat liver or hepatocytes were homogenized in $10 \mathrm{mmol} / \mathrm{L}$ Tris- $\mathrm{HCl}, \mathrm{pH} 7.5$, and $0.3 \mathrm{~mol} / \mathrm{L}$ sucrose buffer. Twenty micrograms of proteins from the cytosolic fractions were loaded onto $10 \%$ sodium dodecyl sulfate-polyacrylamide gel electrophoresis gels and electrophoresed as described previously. ${ }^{30}$ Proteins were electrotransferred to nitrocellulose membranes using $20 \mathrm{mmol} / \mathrm{L}$ of Tris- $\mathrm{HCl}$, pH 7.5, containing $20 \%$ methanol. SAM syn- thetase was detected by using a rabbit antiserum raised against purified rat liver-specific enzyme ${ }^{31}$ and goat anti-rabbit IgG horseradish peroxidase conjugate (Bio Rad, Ritchmond, CA) antibody. Blots were developed by chemiluminiscence using DuPont New England Nuclear Corp. Reinassance reagents (Boston, MA).

Determination of SAM Levels. For SAM determination, liver samples of 100-200 mg were deproteinized by homogenization in $1 \mathrm{~mL}$ $10 \%$ trichloroacetic acid dissolved in $0.05 \mathrm{~N} \mathrm{HCl}$ containing 20,000 dpm of $\left[{ }^{3} \mathrm{H}\right.$-methyl]SAM at $4^{\circ} \mathrm{C}$. Trichloroacetic acid was eliminated by three successive washes with diethylether saturated with $0.05 \mathrm{~N}$ $\mathrm{HCl}$, and samples were lyophilized. Samples were then resuspended in $100 \mu \mathrm{L}$ of $10 \mathrm{mmol} / \mathrm{L}$ of ammonium formate, $\mathrm{pH} \mathrm{4}$, and analyzed by high-performance liquid chomatography using an Ultrasil CX column $(46 \times 250 \mathrm{~mm}$; particle size, $10 \mu \mathrm{m})($ Beckman Instruments, Inc., Palo Alto, CA). After a 5-minute washing period with $0.01 \mathrm{~mol} /$ $\mathrm{L}$ of ammonium formate, $\mathrm{pH} 4.0$, the elution was performed with a 50 -minute linear gradient from $0.01 \mathrm{~mol} / \mathrm{L}$ to $0.8 \mathrm{~mol} / \mathrm{L}$ ammonium formate, $\mathrm{pH} 4.0$, at a flow rate of $1 \mathrm{~mL} / \mathrm{min}$. The concentration of SAM was calculated by measuring absorbance at $254 \mathrm{~nm}$. The recovery was determined by measuring the amount of radioactivity present in a 5- $\mu \mathrm{L}$ aliquot of the sample that was injected.

Statistical Analysis. The data shown are the means \pm SEM of three to four experiments, each one performed with four to eight animals. Statistical significance was estimated with Student's $t$ test for unpaired observations. A $P$ value $<.05$ was considered significant. In studies of RNA (Northern blot) or protein (Western blot) determination, linear correlation between increasing amounts of input RNA or protein and signal intensity were observed (correlation coefficient of $>0.9)$

\section{RESULTS}

The pattern of expression of both liver-specific and extrahepatic SAM synthetase in developing rat liver was determined by Northern blot, using specific cDNA probes. As previously reported, ${ }^{9,10}$ the liver-specific cDNA probe failed to cross-hybridize with the mRNA for the extrahepatic isoenzyme and vice versa.

As shown in Fig. 1, the content of liver-specific SAM synthetase mRNA detected in pooled livers derived from animals of 20-22 days of gestation is rather low, although it increases progressively until birth. Immediately after birth, the rate of increase rises sharply, resulting in an approximately 10-fold change in the mRNA levels. These levels then remain constant at least until 10 days of age but decrease slightly by adulthood. The expression profile shown by the extrahepatic SAM synthetase mRNA falls into a markedly different pattern. The highest levels are detected at day 20 of gestation and decrease toward birth, increasing threefold in the newborn. Subsequently, a rapid reduction in the mRNA content is observed 3 hours after birth, returning to the value measured the last day of gestation. Then, it remains essentially constant throughout the first 20 days of postnatal life, reaching the lowest concentration in the adult rat. These results were reproduced without significant variations in four independent experiments. It is worth noting that blots hybridized with the extrahepatic SAM synthetase probe were subjected to an exposure 10 times longer than when hybridized with the liver-specific SAM synthetase probe, although the specific activity of both probes was similar. It is therefore concluded that, in general, outstanding differences exist in net expression of both mRNAs, and these differences enlarge throughout development, as judged by the intensity ratio of the corresponding signals (Fig. 1B).

Albumin and AFP levels were also determined as a control for the assessment of the developmental status of the tissue. The expression of both mRNAs followed the expected pattern. ${ }^{32,33}$ Thus, albumin mRNA content increased in late fetal life and persisted to adulthood at comparable levels. The amount of AFP also increased throughout the late fetal period but decreased after birth and became undetectable at day 20 of postnatal life. It is interesting to note that liver-specific SAM synthetase could be a reliable indicator of the differenti- 
A Liver-specific SAM-synthetase

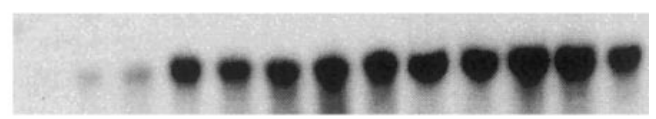
$x_{1}=$

Extrahepatic SAM-synthetase

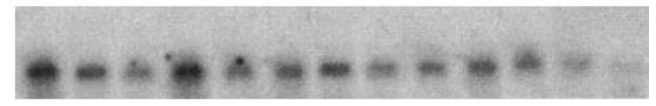

Albumin

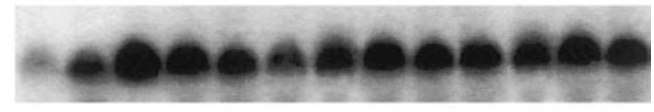

$\alpha$-Fetoprotein

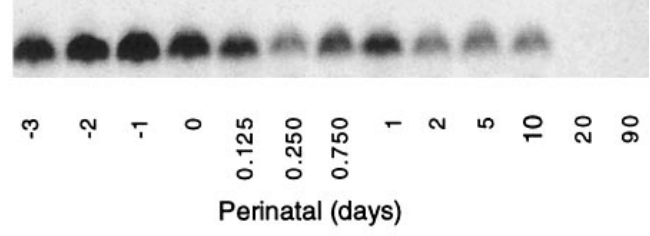

B

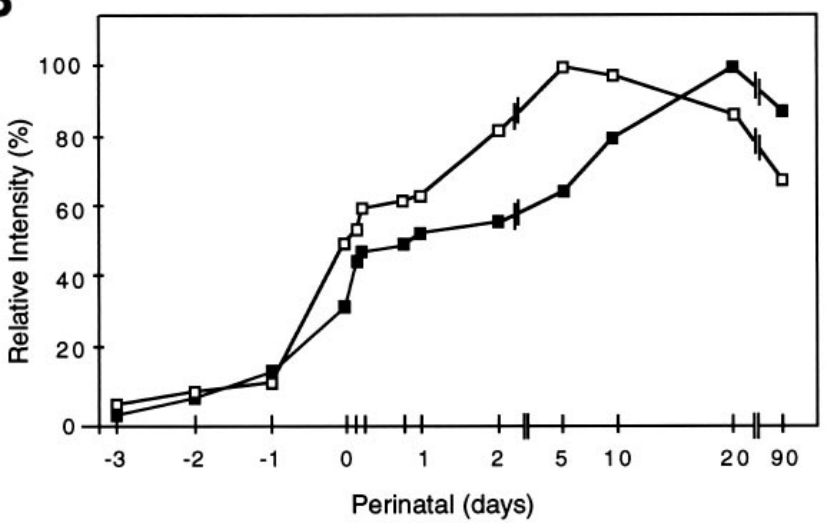

FIG. 1. Developmental regulation of liver-specific and extrahepatic SAM synthetase mRNAs in rat liver. (A) Northern blot of total RNA (30 $\mu \mathrm{g})$ derived from rat livers at the indicated stages of development. For fetal and newborn stages, livers were pooled from several individuals. (A) Signal obtained after hybridization of the membrane with $\left[{ }^{32} \mathrm{P}\right] \mathrm{cDNA}$ probe for liver-specific SAM synthetase. A longer exposure of the lanes corresponding to fetal stages is shown below. The same blot was hybridized subsequently to extrahepatic SAM synthetase, albumin, and AFP probes. The exposure period of the blot after hybridization with the extrahepatic SAM synthetase probe was 10 times longer than for the corresponding liver-specific SAM synthetase probe. (B) The intensity ratio of liver-specific SAM synthetase/extrahepatic SAM synthetase (ם) and liver-specific SAM synthetase/albumin ( $\square$ ) mRNA bands obtained by densitometric scanning of the blots and normalized against 18S ribosomal RNA. Values are expressed as the percentage relative to the point that yielded the highest ratio. Statistical significance is as follows: $P<.001$, prenatal days vs. postnatal period. The figure reflects a typical result representative of four independent experiments.

ated state of the hepatocyte, as deduced by the liver-specific SAM synthetase/albumin ratio shown (Fig. 1B).

It is well known that fetal liver contains a high population of hematopoietic cells among hepatocytes, and a sharp decrease in its quantity as birth approaches can contribute to developmental changes in enzyme and isoenzyme contents. ${ }^{34}$ This factor could be influencing the results derived from fetal samples, especially those concerning the expression of the mRNA for the extrahepatic isoenzyme. Therefore, we next examined whether the mRNA expression profiles found in the total liver also takes place in isolated hepatocytes. Albumin and AFP mRNA content were also measured as markers for hepatocyte lineage. As shown in Fig. 2, the expression profiles of the four mRNA species analyzed in hepatocytes from fetuses of 20- to 22-day gestation, newborn, and adult rats closely resembles that found in the total liver, except for AFP, whose levels appear to be relatively greater 3 days before birth. The intensity ratio of the signals yielded by liverspecific and extrahepatic SAM synthetase mRNA bands in hepatocytes (Fig. 2B) is also similar to that observed in the total liver. Therefore, it is concluded that changes in the developmental program of both mRNAs occur in the same cell type.

To further define the molecular basis for the regulation of liver-specific SAM synthetase in different developmental stages, we also determined the content of the specific protein. Extracts of cytosolic proteins derived from aliquots of the same samples used for Northern analysis were subjected to immunoblotting. As shown in Fig. 3, changes in the specific protein during development show a trend similar to the corre-

\section{A \\ Liver-specific SAM-synthetase}

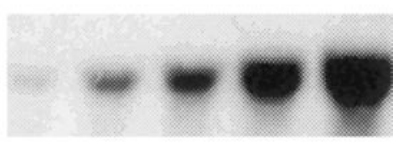

\section{Extrahepatic SAM-synthetase}

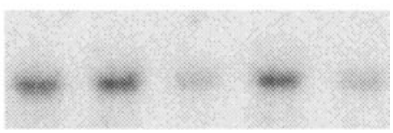

Albumin

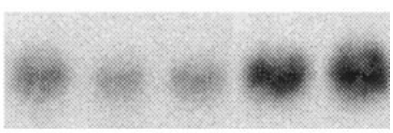

$\alpha$-Fetoprotein

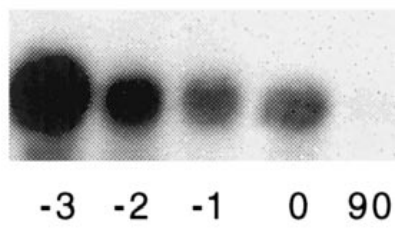

B
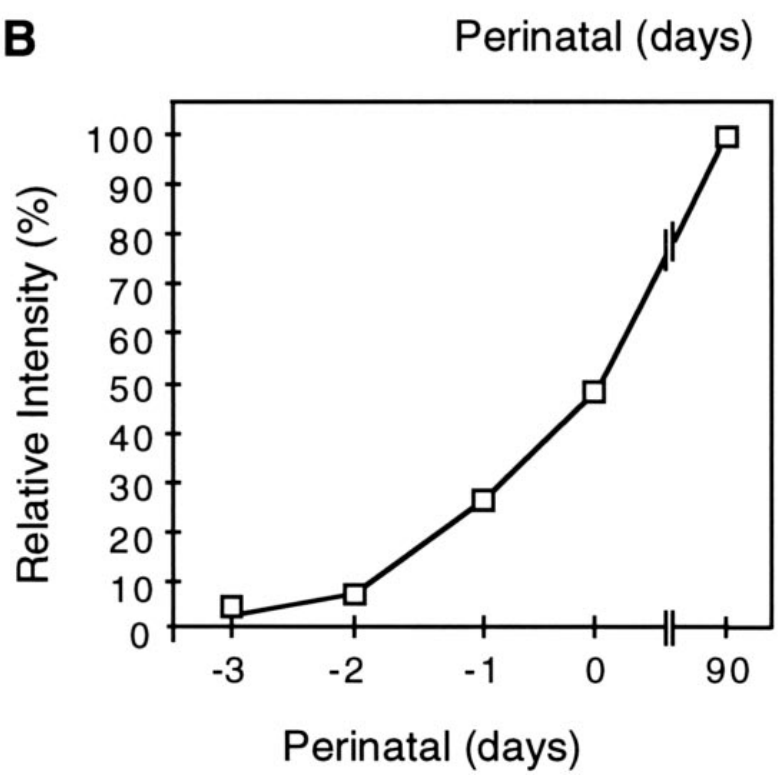

FIG. 2. (A) Northern blot prepared from equal amounts ( $30 \mu \mathrm{g})$ of total RNA from isolated rat hepatocytes at different developmental stages was hybridized sequentially with the indicated probes. The time of exposure of the blots was as detailed in Fig. 1. (B) Intensity ratio of liver-specific SAM synthetase/extrahepatic SAM synthetase mRNA bands. Results shown are representative of four experiments. 
A
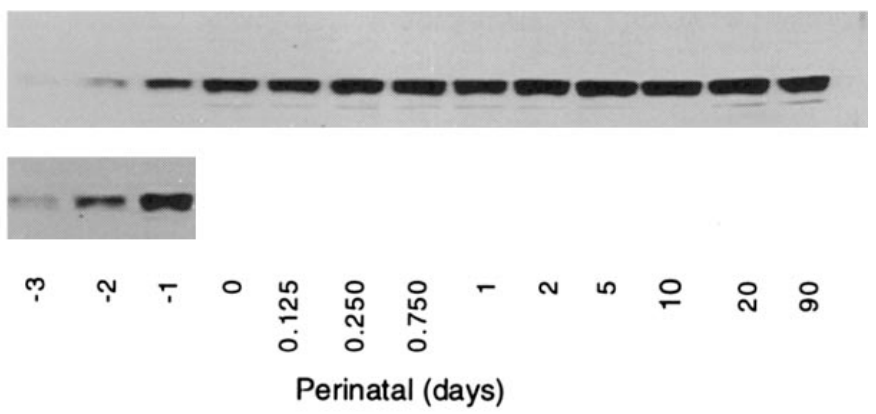

B

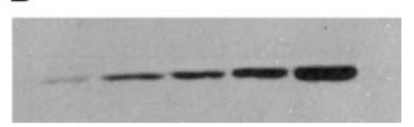

ฺุ

Perinatal (days)

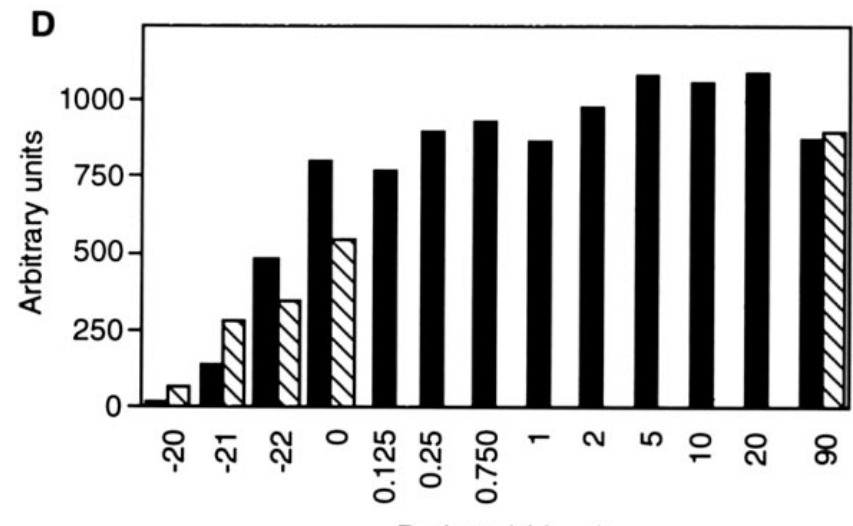

Perinatal (days)

FIG. 3. Developmental regulation of immunoreactive liver-specific SAM synthetase. Equal amounts of cytosolic proteins $(20 \mu \mathrm{g})$ derived from (A) rat liver or (B) rat hepatocytes at the indicated developmental stages were fractionated by $10 \%$ sodium dodecyl sulfate-polyacrylamide gel electrophoresis and subjected to immunoblot analysis with an antibody raised against the liver-specific SAM synthetase (dilution 1:10,000). (C) To test the specificity of the antibody, cytosolic proteins from rat kidney and spleen were also subjected to Western analysis. (D) Densitometric analysis of immunoreactive liver-specific SAM synthetase at different developmental stages in total liver (ם) and isolated hepatocytes $(\mathbb{B})$. Statistical significance is as follows: $P<.001$, prenatal days vs. postnatal period. The figure shows a representative experiment of four experiments.

sponding mRNA expression either in total liver or in hepatocytes. The antibody raised against the liver-specific SAM synthetase did not cross-react with the extrahepatic form because no signal was detected either in kidney or spleen (Fig. 3C), two tissues where only this isoenzyme is expressed.

The marked accumulation of liver-specific SAM synthetase observed immediately after birth suggests that the hormonal changes characteristic of neonatal animals could be the factors responsible for this cut-off switch. An important glucagonemia associated with a decrease in the insulin levels has been considered one of the factors that trigger the regulation of gluconeogenic enzymes. ${ }^{35}$ In addition to these hormones, prolactin reaches a peak in the newborn. ${ }^{36}$ Therefore, we decided to investigate whether by using an ex vivo system of cultured fetal hepatocytes ( 21 days of gestation) these hormones could reproduce the expression patterns of SAM synthetase isoenzymes observed after birth. As shown in Fig.
4, when fetal hepatocytes were incubated with a permeant analogue of cAMP, an important up-regulation of the liverspecific SAM synthetase concomitant with a down-regulation of the extrahepatic isoenzyme was observed. When hepatocytes were incubated with insulin, even at concentrations that involve the occupation of the insulin or insulin-like growth factor receptor dexamethasone or prolactin, the behavior of the two messages was the same as in untreated cells. It is of interest to mention that on culture, fetal hepatocytes showed a progressive loss of the mRNA levels for the liver-specific enzyme, which again argues in the sense of an increased expression of this specific isoenzyme as hepatocyte maturation and differentiation develops.

Altogether, the results described above are consistent with the developmental patterns of SAM synthetase activity described previously. ${ }^{15,17}$ To determine whether these changes also correlate with SAM content, the levels of this metabolite at different developmental stages were measured (Fig. 5). Unexpectedly, the concentration of hepatic SAM in fetuses and newborns is significantly greater than that measured in the immediate postnatal periods $(P<.05)$ and similar to the one detected in adult rat.

\section{DISCUSSION}

In the present study, we have delineated the developmental patterns of expression of liver-specific and extrahepatic SAM synthetases by determining the respective mRNA levels. This approach was followed as an accurate way to discriminate both isoenzymes, bearing also in mind that changes in the production of proteins during normal development are controlled primarily at the level of mRNA synthesis. $^{37,38}$

Our results show that a switch in the predominant expression from the extrahepatic to the liver-specific isoenzyme occurs in rat liver in late fetal life. The concentration of the mRNA for the liver-specific SAM synthetase increases from the earliest fetal age studied, increases strikingly after birth, and peaks at age 10 days. Conversely, mRNA levels of the extrahepatic isoenzyme decrease gradually until birth and reach a minimum in the adult life. Interestingly, isolated hepatocytes mimic isoform switching, indicating that both mRNAs are differentially regulated in the same cell type. This finding also excludes the possibility that changes observed in the content of extrahepatic mRNA in total liver could be caused by the contribution of hematopoietic cells present in different proportions at each fetal stage.

Results concerning the presence of liver-specific SAM synthetase mRNA in fetal rat liver differ from previous studies that suggested a lack of expression of this isoenzyme at this developmental stage. ${ }^{18,19}$ This discrepancy may be caused by the different methods used to detect the respective isoenzymes. Another possibility would be that formation of the mRNA does not necessarily determine the time of appearance of the corresponding protein. Indeed, this is the case with albumin and AFP, which are detected 1 day later than their respective mRNAs. ${ }^{39}$ However, Western blot analysis performed with a specific antibody that does not recognize the extrahepatic isoenzyme showed that liver-specific SAM synthetase is present at the same time that the mRNA is detected in both total liver and hepatocytes. Furthermore, the levels of the protein change during liver development in a manner similar to the corresponding mRNA.

Overall, there is a good correlation between the results presented here and the developmental profiles of activity reported previously, ${ }^{15,17}$ suggesting a regulatory mechanism acting primarily at the mRNA level. The involvement of other mechanisms modulating the activity of either isoenzyme at different stages of development cannot be ruled out but, as deduced from the studies by Chase et al., ${ }^{17}$ it seems unlikely. Therefore, as judged by the resulting expression patterns, it 


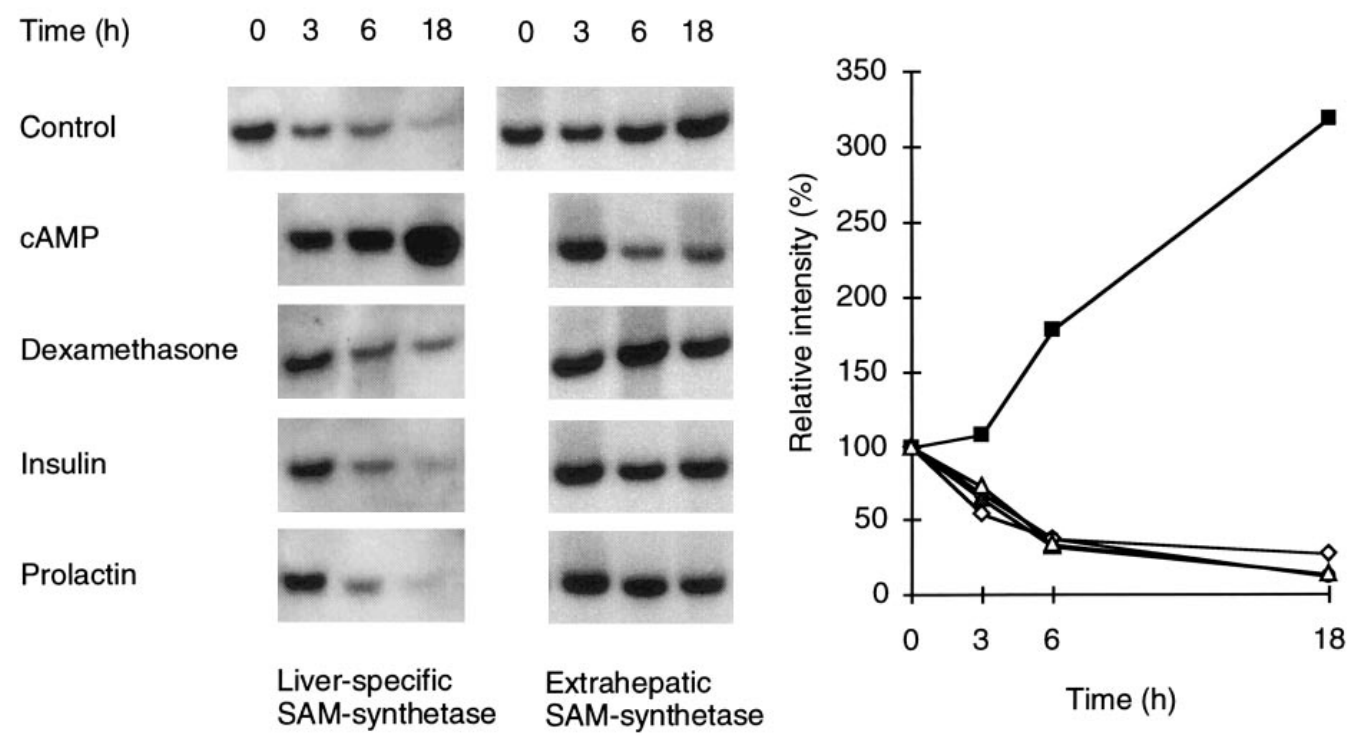

FIG. 4. Effect of hormones on liver-specific and extrahepatic SAM synthetase mRNAs in primary cultures of fetal hepatocytes. Hepatocytes from 21-day-old fetuses were cultured as detailed in Materials and Methods and were incubated for 3, 6 , and 18 hours in the absence or presence of the indicated effectors. (A) Northern blot analysis performed with $30 \mu \mathrm{g}$ of total RNA. Filters were hybridized sequentially with liverspecific and extrahepatic SAM synthetase probes. The time of exposure was as indicated in Fig. 1. (B) Intensity ratio of liver-specific SAM synthetase/extrahepatic SAM synthetase mRNA bands after normalization against $18 \mathrm{~S}$ ribosomal RNA. Results are expressed relative to the value at time zero, which was taken as $100 \%$. The figure reflects a representative experiment of three experiments. ( $\bigcirc)$, Control; $(\diamond)$, dexamethasone; $(\triangle)$, prolactin; $(\boldsymbol{\Delta})$, insulin; $(\boldsymbol{\square})$ ph-cAMP. is conceivable to speculate that, in late gestation, the SAM synthetase activity reported must be attributed to a mixed action of both isoenzymes. The rapid increase in the activity detected after birth can be mainly associated with the sharp increase in the expression of the liver-specific form. Measurements of activity in the postnatal life also would be attributed essentially to the action of this isoenzyme because the expression of extrahepatic SAM synthetase decreases after birth and seems to be almost residual in the adult life.

Whether the mRNA expression pattern of the liver-specific

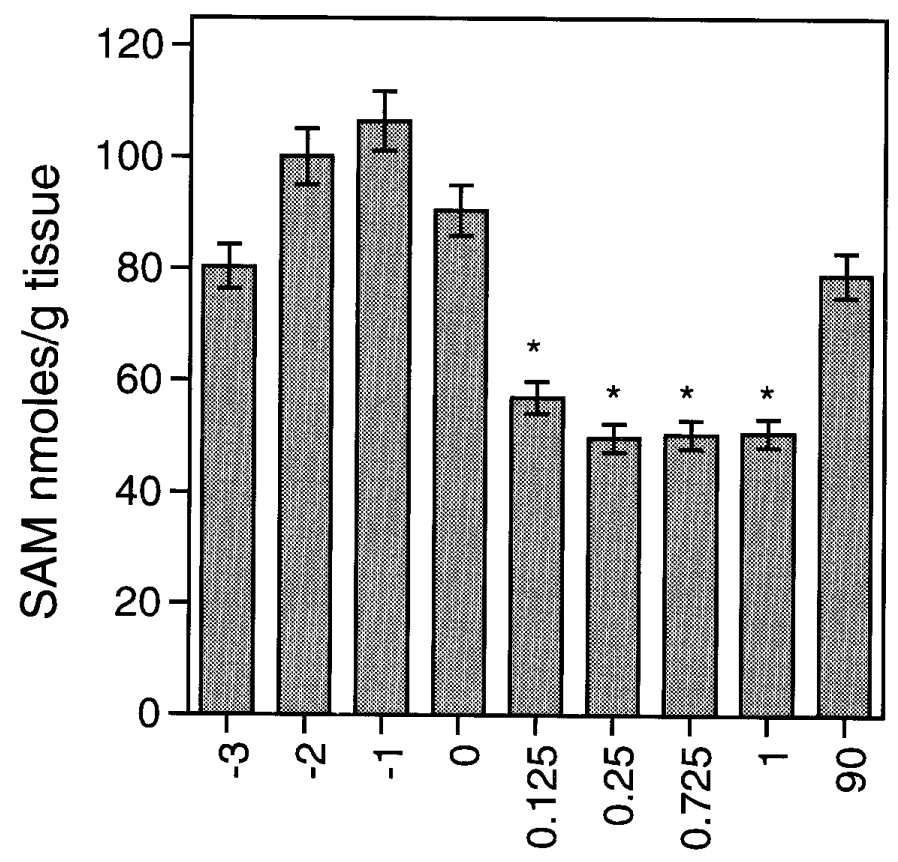

\section{Perinatal (days)}

FIG. 5. Hepatic concentration of SAM in rats at different stages of development. Results are shown as mean \pm SEM of four different preparations. Values from fetuses, newborns, and adults were significantly different than those measured in the immediate postnatal group $(P<.05)$.
SAM synthetase is caused by the modulation of gene transcription and/or stability of the mRNA is not known. Most of the liver-specific gene products found to be dramatically induced at birth are regulated at the transcriptional level. ${ }^{40,41}$ This regulation is commonly dependent on glucocorticoids and hormones that elevate the intracellular level of cAMP. ${ }^{35,38}$ The mechanism that controls the switch of SAM synthetase isoenzymes also appears to be related to the important hormonal changes that occur during perinatal transition. The ability of cAMP to evoke SAM synthetase isoenzyme switching in primary cultures of fetal hepatocytes suggests that glucagon is the hormonal stimulus that triggers this regulation. In fact, the insulin/glucagon ratio decreases markedly in response to the well-known postnatal hypoglycemia, resulting in a concomitant increase in the concentration of intracellular hepatic cAMP. ${ }^{42}$ The physiological relevance of these metabolic changes has been widely shown, being involved in the formation of many hepatic enzymes that accumulate precipitously after birth, such as those involved in the control of carbohydrate metabolism. ${ }^{35}$

An interesting finding is that liver-specific SAM synthetase expression parallels the switch on of the albumin gene, showing a notorious increase around delivery that remains stable up until the adult life. Also, changes in development in AFP and liver-specific SAM synthetase mRNAs either in total liver or in hepatocytes occur in opposite directions. These results suggest that liver-specific SAM synthetase could be a trait of the differentiated state of the hepatocyte. Related to this, it is worth noting that hepatocyte culturing is accompanied by a loss of the liver-specific isoenzyme mRNA, an effect readily attributed to the classic phenomenon of dedifferentiation of primary cultures. It also should be mentioned that, in a dedifferentiated hepatic cell line such as rat hepatoma H35, the levels of the liver-specific SAM synthetase are comparatively much lower than in hepatocytes (Gil B, et al., Unpublished observation, October, 1995).

The necessity of modulating SAM synthetase expression as a function of development must be oriented to cope with the changing demands of SAM. In this context, intriguing questions derive from the finding that, in contrast to the overall SAM synthetase expression pattern, levels of SAM are significantly greater in late gestation and after birth than in immediate postnatal periods. This may be interpreted in the light of previous studies performed in humans ${ }^{43}$ and 
rats, ${ }^{44}$ which showed that marked alterations in hepatic SAM synthetase do not necessarily result in significant changes in SAM levels, a finding that was considered as indicative that the rate of utilization of this metabolite is accommodated to the rate of its synthesis. ${ }^{43}$ Another possible explanation is related to a putative maternal supply of SAM. Consequently, with this hypothesis, the sharp increase in expression of liverspecific SAM synthetase immediately after birth may be produced in response to the loss of the maternal source.

It can be finally concluded that SAM synthetase activity present in fetal hepatocytes is sufficient to cope with the supply of SAM to the cell, a situation that, apparently, does not apply to the postnatal hepatocyte. Unraveling of the molecular basis for the necessary commitment of the expression of a liver-specific SAM synthetase can contribute to a better understanding of mammalian liver physiology.

Acknowledgment: The authors thank Drs. J. L. Danan and I. Fabregat for the generous gift of albumin and AFP; and Drs. E. Alonso-Aperte, J. Mingorance, and G. VarelaMoreiras for the critical reading of the manuscript.

\section{REFERENCES}

1. Greengard O. Enzymic differentiation in mammalian liver. Science 1969; 163:891-895.

2. Greengard $\mathrm{O}$. The developmental formation of enzymes in rat liver. In: Litwak G, ed. Biochemical action of hormones. New York: Academic, 1970; 1:53-87.

3. Cantoni GL. Biochemical methylations: selected aspects. Annu Rev Biochem 1975; 44:435-451.

4. Finkelstein JD, Martin JJ. Methionine metabolism in mammals: adaptation to methionine excess. J Biol Chem 1986;261:1582-1587.

5. Mudd SH, Poole JR. Labile methyl balance for normal humans on various dietary regimens. Metabolism 1975;24:721-735.

6. Kotb M, Geller AM. Methionine adenosyltransferase: structure and function. Pharmacol Ther 1993;59:125-143.

7. Mato JM, Alvarez L, Corrales F, Pajares MA. S-adenosylmethionine and the liver. In: Arias IM, Boyer JL, Fausto N, Jakoby WB, Schachter DA, Shafritz DA, eds. The liver: biology and pathobiology. Ed 3. New York: Raven, 1994:461-470

8. Horikawa S, Ishikawa M, Ozasa H, Tsukada K. Isolation of a cDNA encoding the rat liver S-adenosylmethionine synthetase. Eur J Biochem 1989; 184:497-501.

9. Alvarez L, Asunción M, Corrales F, Pajares MA, Mato JM. Analysis of the $5^{\prime}$ non-coding region of rat liver S-adenosylmethionine synthetase mRNA and comparison of the Mr deduced from the cDNA sequence and the purified enzyme. FEBS Lett 1991;290:142-146.

10. Horikawa S, Sasuga J, Shimizu K, Ozasa H, Tsukada K. Molecular cloning and nucleotide sequence of cDNA encoding the rat kidney S-adenosylmethionine synthetase. J Biol Chem 1990;265:13683-13686.

11. Horikawa S, Tsukada K. Molecular cloning and nucleotide sequence of cDNA encoding the human liver S-adenosylmethionine synthetase. Biochem Int 1991;25:81-90.

12. Alvarez L, Corrales F, Martín-Duce A, Mato JM. Characterization of a full-length cDNA encoding human liver S-adenosylmethionine synthetase: tissue-specific gene expression and mRNA levels in hepatopathies. Biochem J 1993;293:481-486.

13. Horikawa S, Tsukada K. Molecular cloning and developmental expression of a human kidney S-adenosylmethionine synthetase. FEBS Lett 1992, $312: 37-41$

14. De la Rosa J, Ostrowski J, Hryniewicz MM, Kredich NM, Kotb M, LeGros HL Jr, Valentine M, Geller AM. Chromosomal localization and catalytic properties of the recombinant $\alpha$ subunit of human lymphocyte methionine adenosyltransferase. J Biol Chem 1995;270:21860-21868.

15. Hancock RL. S-Adenosylmethionine-synthesizing activity of normal and neoplastic mouse tissue. Cancer Res 1966;26:2425-2430.

16. Finkelstein JD. Methionine metabolism in mammals: effects of age, diet, and hormones on three enzymes of the pathway in rat tissues. Arch Biochem Biophys 1967;122:583-590.

17. Chase HP, Volpe JJ, Laster L. Transsulfuration in mammals: fetal and early development of methionine-activating enzyme and its relation to hormonal influences. J Clin Invest 1968;47:2099-2108.
18. Okada G, Watanabe Y, Tsukada K. Changes in patterns of S-adenosylmethionine synthetases in fetal and postnatal rat liver. Cancer Res 1980; 40:2895-2897.

19. Horikawa S, Ozasa H, Ota K, Tsukada K. Immunohistochemistry analysis of rat S-adenosylmethionine synthetase isozymes in developmental liver. FEBS Lett 1993;330:307-311.

20. Liau MC, Chang CF, Belanger L, Grenier A. Correlation of isoenzyme patterns of S-adenosylmethionine synthetase with fetal stages and pathological states of the liver. Cancer Res 1979;39:162-169.

21. Di Marco PN, Ghisalberti AV, Pearce PH, Oliver IT. Postnatal changes in blood glucose, phosphopyruvate carboxylase and tyrosine aminotransferase after normal birth and premature delivery in the rat. Biol Neonate 1976;30:205-215

22. Martín-Sanz P, Cascales M, Boscá L. Fructose 2,6-biphosphate in isolated foetal hepatocytes. FEBS Lett 1987; 225:37-42.

23. Martín-Sanz P, Cascales M, Boscá L. Glucagon-induced in fructose 2,6biphosphate and 6-phosphofructo-2-kinase in cultured rat foetal hepatocytes. Biochem J 1989;257:795-779.

24. Alvarez L, Mingorance J, Pajares MA, Mato JM. Expression of rat liver S-adenosylmethionine synthetase in Escherichia coli results in two active oligomeric forms. Biochem J 1994;301:557-561.

25. Sanger F, Nicklen S, Coulson AR. DNA sequencing with chain-terminating inhibitors. Proc Natl Acad Sci U S A 1977;74:5463-5467.

26. Sargent TD, Wu JR, Sala-Trepat JM, Wallace RB, Reyes AA, Bommer J. The rat albumin serum gene: analysis of cloned sequences. Proc Natl Acad Sci U S A 1979; 76:3256-3260.

27. Jagodzinski LL, Sargent TD, Yang M, Glackin C, Bommer J. Sequence homology between RNAs encoding rat $\alpha$-fetoprotein and rat serum albumin. Proc Natl Acad Sci U S A 1981;78:3521-3525.

28. Chomczynski P, Sacchi N. Single-step method of RNA isolation by acid guanidinium thiocyanate-phenol-chloroform extraction. Anal Biochem 1987;162:156-159

29. Casado M, Boscá L, Martín-Sanz P. Rat liver messenger ribonucleic acid and enzyme activity of 6-phosphofructo 2-kinase/fructose 2,6-biphosphatase impairment during the late period of pregnancy. Endocrinology 1993; 133:1044-1050.

30. Laemmli UK. Cleavage of structural proteins during the assembly of the head of bacteriophage T4. Nature 1970;227:680-685.

31. Mingorance J, Alvarez L, Sánchez-Góngora E, Mato JM, Pajares MA. Sitedirected mutagenesis of rat liver S-adenosylmethionine synthetase. Identification of a cysteine residue critical for the oligomeric state. Biochem $J$ 1996;315:761-766.

32. Tilghman SM, Belayew A. Transcriptional control of the murine albumin/ $\alpha$-fetoprotein locus during development. Proc Natl Acad Sci U S A 1982; 79:5254-5257

33. Muglia L, Locker J. Developmental regulation of albumin and $\alpha$-fetoprotein gene expression in the rat. Nucleic Acids Res 1984;12:6751-6762.

34. Jones CT, Rolph TP. Metabolism during fetal life: a functional assessment of metabolic development. Physiol Rev 1985;65:357-430.

35. McGranne MM, Yun JS, Patel YM, Hanson RW. Metabolic control of gene expression: in vivo studies with transgenic mice. Trends Biochem Sci 1992; 17:40-44.

36. Yohkaichiya T, O'Connor A, de-Kretser DM. Circulating immunoreactive inhibin, gonadotropin, and prolactin levels during pregnancy, lactation, and postweaning estrous cycle in the rat. Biol Reprod 1991;44:6-12

37. Maniatis T, Goodburn S, Fisher JA. Regulation of inducible and tissuespecific gene expression. Science 1987;236:1237-1245.

38. Zaret KS. Genetic control of hepatocyte differentiation. In: Arias IM, Boyer JL, Fausto N, Jakoby WB, Schachter DA, Shafritz DA, eds. The liver: biology and pathobiology. Ed 3. New York: Raven, 1994:461-470.

39. Shiojiri N, Lemire JM, Fausto N. Cell lineages and oval cell progenitors in rat liver development. Cancer Res 1991;51:2611-2620.

40. Derman E, Krauter K, Walling L, Weinberg C, Ray M, Darnell JE Jr. Transcriptional control in the production of liver-specific mRNAs. Cell 1981:23:731-739.

41. Panduro A, Shalaby F, Shafritz DA. Changing patterns of transcriptional and postranscriptional control of liver-specific gene expression during rat development. Genes Dev 1987; 1:1172-1182.

42. Girard J, Cuendet GS, Marliss EB, Kervran A, Rieutort M, Assan R. Fuels hormones, and liver metabolism at term and during the early postnatal period in the rat. J Clin Invest 1973;53:3190-3200.

43. Cabrero C, Martín-Duce A, Ortiz P, Alemany S, Mato JM. Specific loss of the high-molecular-weight form of S-adenosylmethionine synthetase in human liver cirrhosis. HEPATOLOGY 1988;8:1530-1534.

44. Corrales F, Giménez A, Alvarez L, Caballería J, Pajares MA, Andreu H, Parés A, et al. S-adenosylmethionine treatment prevents carbon tetrachloride-induced S-adenosylmethionine synthetase inactivation and attenuates liver injury. HePATOLOGY 1992;16:1022-1027. 